(C) by Oldenbourg Wissenschaftsverlag, München

\title{
Crystal structure of 1,4-diazoniabicyclo[2.2.2]octane diiodide monohydrate
}

\author{
Sebastian Maderlehner and Arno Pfitzner* \\ Institut für Anorganische Chemie, Universität Regensburg, Universitätsstraße 31, 93040 Regensburg, Germany
}

In memoriam Professor Friedrich Liebau

Received December 19, 2011, accepted January 5, 2012

Published online: July 9, 2012

\section{Alkylammonium halide / Hydrogen bonding / \\ Phase transition / Solid hydrate}

\begin{abstract}
. 1,4-diazoniabicyclo[2.2.2]octane diiodide monohydrate was synthesized by protonation of 1,4-diazabicyclo[2.2.2] octane (DABCO) with an excess of concentrated hydroiodic acid in water. It forms colourless rodlike crystals. At room temperature an orthorhombic unit cell, space group $C m c 2_{1}, a=7.781(2) \AA, b=13.010$ (3) $\AA$, $c=11.610(2) \AA, V=1175.3(4) \AA^{3}, Z=4$, is observed. Both nitrogen atoms bear a proton. The hydrate water molecule within the compound is statistically disordered on a site besides a crystallographic mirror plane at room temperature. DSC measurements indicate a phase transition at about $-10{ }^{\circ} \mathrm{C}$. A single crystal X-ray diffraction measurement at $123 \mathrm{~K}$ reveals a primitive unit cell, space group $\quad P c a 2_{1}, \quad a=12.8835(2) \AA, \quad b=7.6819(1) \AA$, $c=11.4392(2) \AA, \quad V=1132.16(3) \AA^{3}, Z=4$. The water molecule with its hydrogen atoms is well ordered at this temperature. Two almost linear hydrogen bonds $\mathrm{O}-\mathrm{H} \cdots \mathrm{I}$ are formed. The formation of hydrogen bonds is also detected by IR-spectroscopy with $\mathrm{O}-\mathrm{H}$ stretching frequencies at $\bar{v}=3403 \mathrm{~cm}^{-1}$ and $\bar{v}=3354 \mathrm{~cm}^{-1}$, respectively.
\end{abstract}

\section{Introduction}

1,4-Diazabicyclo[2.2.2] octane (DABCO) is used in various applications. Two important ones are the use as a scavenger of acids in elimination reactions and as a catalyst in organic synthesis, respectively [1]. Twofold protonation of DABCO is only achieved with strong acids, because of the low $\mathrm{p} K_{\mathrm{a}}$ value of the di-cationic $\mathrm{DABCOH}_{2}^{2+}$ of 2.97 [2] which makes it more acidic than formic acid $\left(\mathrm{p} K_{\mathrm{a}}=3.752\right)$ or hydrofluoric acid $\left(\mathrm{p} K_{\mathrm{a}}=3.189\right)$ [3, 4]. The title compound 1,4-diazoniabicyclo[2.2.2] octane diiodide monohydrate (1) was obtained by using an excess of $\mathrm{HI}$ to achieve full twofold protonation. DABCO dihydrochloride and DABCO dihydrochloride dihydrate are de-

* Correspondence author (e-mail: Arno.Pfitzner@chemie.uni-regensburg.de) scribed in Refs. [5, 6]. They both can be obtained by solving DABCO in diluted hydrochloric acid. A methanol solvate of DABCO dihydroiodide has been synthesized in a high pressure transformation of $\mathrm{DABCO}$ hydroiodide in methanol [7]. DABCO hydroiodide monohydrate has recently been observed in high pressure experiments on DABCO hydroiodide. Two polymorphs depending on the applied pressure are reported [8]. In all of these compounds the ammonium $\mathrm{N}-\mathrm{H}$ groups of the $\mathrm{DABCO}$ cations are forming hydrogen bonds with different acceptor atoms or molecules present in the crystalline compound. In the water free dihydrochloride all chloride anions act as hydrogen bond acceptors. A chain structure is formed by hydrogen bonds in DABCO dihydrochloride dihydrate. The cation forms one hydrogen bond to a chloride ion and one to a hydrate water molecule. The water molecules donate further hydrogen bonds to chloride ions thus forming the chain structure. Contrary, the cations form hydrogen bonds exclusively towards the oxygen atoms of the solvate molecules in the methanol solvate. The methanol molecules donate further hydrogen bonds to the iodide ions or to neighbouring solvate molecules. The ammonium $\mathrm{N}-\mathrm{H}$ groups of the cation are donating hydrogen bonds to an iodide anion and to a disordered hydrate water molecule in 1 similar to DABCO dihydrochloride dihydrate. Herein, we report on the crystal structure of 1,4-diazoniabicyclo[2.2.2] octane diiodide monohydrate at room temperature and the formation of an ordered hydrogen network upon cooling. A phase transition at about $-10{ }^{\circ} \mathrm{C}$ is driven by hydrogen bonds and results in a well ordered structure.

\section{Experimental}

$2 \mathrm{~g}$ (17.8 mmol) 1,4-diazabicyclo[2.2.2] octane (Sigma-Aldrich, 98\%) were dissolved in water and $7 \mathrm{~mL}$ (ca. $56 \mathrm{mmol}$, ca. 3 eq.) of concentrated hydroiodic acid (Merck, 57\% extra pure) were added slowly. The solution was filtered off immediately to remove impurities of crystalline iodine and dried in a vacuum yielding $6.56 \mathrm{~g}$ $(17 \mathrm{mmol}, 96 \%)$ of a colourless product of rod-like crys- 


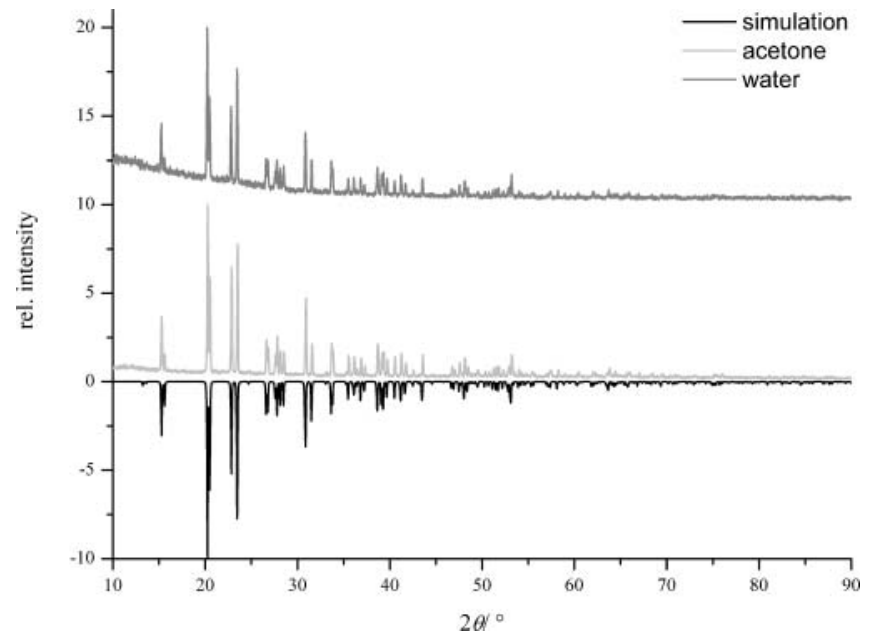

Fig. 1. XRD pattern of 1; simulation with single crystal data (293 K) and measured after protonation in acetone and water, respectively.

tals. An identical product was obtained when the reaction was performed in organic solvents such as acetone or acetonitrile instead of water, see Fig. 1. Crystals suitable for single crystal X-ray diffraction were mounted on and glued to a glass fibre. Diffraction data were collected on a STOE IPDS I at room temperature, see Table 1 for details. Data were corrected for Lorentz and polarization effects, and absorption was corrected numerically after a semiempiric optimization of the crystal shape with the X-SHAPE routine [9]. The structure was solved by direct methods using SIR92 [10] followed by a full-matrix least-squares refinement with SHELXL97 [11]. Hydrogen atoms of the ethylene groups and at nitrogen were attached to the heavier atoms with a riding model for the room temperature data set (HFIX 23 for ethylene groups, HFIX 13 for nitrogen atoms). Further details of the measurement and refinement are collected in Table 1 . The phase purity of the initial reaction product was checked by X-ray powder diffraction on a STOE STADI P, CuK $K_{\alpha 1}(\lambda=1.54056 \AA)$ with a position sensitive detector and transmission setup. Raman- and IR-spectra were recorded on a Varian FT Raman module coupled on a Varian FTS 7000e spectrometer equipped with a $\mathrm{Nd}$ : YAG laser (excitation wavelength $\lambda=1064 \mathrm{~nm}$ ) and a liquid nitrogen cooled germanium detector with a resolution of $1 \mathrm{~cm}^{-1}$. The spectra were processed with the Varian Resolution Pro Software [12]. DSC measurements were performed with a heating/cooling rate

Table 1. Crystal data and structure refinement of $1{ }^{*}$

\begin{tabular}{|c|c|c|}
\hline Empirical formula & $-\mathrm{C}_{6} \mathrm{H}_{16} \mathrm{I}_{2} \mathrm{~N}_{2} \mathrm{O}-$ & \\
\hline Formula weight & $-386.01 \mathrm{~g} \mathrm{~mol}^{-1}-$ & \\
\hline Temperature & $293 \mathrm{~K}$ & $123 \mathrm{~K}$ \\
\hline Wavelength & $-0.71073 \AA-$ & \\
\hline Crystal system & -orthorhombic- & \\
\hline Space group & $C m c 2_{1}$ (No. 36) & $\mathrm{Pca}_{1}$ (No. 29) \\
\hline Unit cell dimensions & $a=7.781(2) \AA$ & $a=12.8835(2) \AA$ \\
\hline & $b=13.010(3) \AA$ & $b=7.6819(1) \AA$ \\
\hline & $c=11.610(2) \AA$ & $c=11.4395(2) \AA$ \\
\hline Volume, $Z$ & $1175.3(4) \AA^{3}, 4$ & $1132.16(3) \AA^{3}, 4$ \\
\hline Density $\varrho$ (calculated) & $2.182 \mathrm{~g} / \mathrm{cm}^{3}$ & $2.265 \mathrm{~g} / \mathrm{cm}^{3}$ \\
\hline $\begin{array}{l}\text { Absorption coefficient } \\
\mu\left(\operatorname{Mo} K_{\alpha}\right)\end{array}$ & $5.313 \mathrm{~mm}^{-1}$ & $5.515 \mathrm{~mm}^{-1}$ \\
\hline$F_{000}$ & 720 & 720 \\
\hline Crystal size & $0.2 \times 0.2 \times 0.2 \mathrm{~mm}^{3}$ & $0.2 \times 0.1 \times 0.1 \mathrm{~mm}^{3}$ \\
\hline$\theta$ range for data collection & 3.05 to $25.41^{\circ}$ & 3.09 to $32.71^{\circ}$ \\
\hline Limiting indices & $-9 \leq h \leq 9 ;-15 \leq k \leq 15 ;-14 \leq l \leq 13$ & $-19 \leq h \leq 19 ;-11 \leq k \leq 11 ;-17 \leq l \leq 16$ \\
\hline Reflections collected & 6435 & 15555 \\
\hline Independent reflections & $1164[R(\mathrm{int})=0.0442]$ & $3848[R(\mathrm{int})=0.0268]$ \\
\hline Data/restraints/parameters & $1164 / 1 / 64$ & $3848 / 1 / 148$ \\
\hline Structure solution & -SIR $92[10]-$ & \\
\hline Structure refinement & -SHELXL $97[11]-$ & \\
\hline Absorption correction & numerical, X-RED/X-SHAPE [9] & numerical, CrysAlisPro [13] \\
\hline $\operatorname{Goof}^{a} S$ & 1.100 & 1.033 \\
\hline Final $R^{b}$ indices $[I>2 \sigma(I)]$ & $R_{1}=0.0362, w R_{2}=0.0893$ & $R_{1}=0.0213, w R_{2}=0.0431$ \\
\hline$R$ indices (all data) & $R_{1}=0.0375, w R_{2}=0.0899$ & $R_{1}=0.0241, w R_{2}=0.0440$ \\
\hline Flack parameter & $-0.03(9)$ & $0.00(2)$ \\
\hline weighting parameters ${ }^{c}$ & $a=0.0559, b=3.4867$ & $a=0.0204, b=0$ \\
\hline$\Delta \varrho_{\max }, \Delta \varrho_{\min }$ & $1.330,-0.840 \mathrm{e}^{-3}$ & $0.973,-0.463 \mathrm{e}^{-3}$ \\
\hline
\end{tabular}

a: s. Eq. 1; b: s. Eqs. 2 and 3; c: s. Eqs. 4 and 5

* Further details on the crystal structure investigations may be obtained from the Cambridge Crystallographic Data Centre (CCDC), CCDC, 12 Union Road, Cambridge CB2 1EZ, UK (www.ccdc.cam.ac.uk) on quoting the depository number CCDC861183 (293 K) and CCDC861184 (123 K) 
of $10{ }^{\circ} \mathrm{C} \min ^{-1}$ on a Mettler Toledo DSC 30 to check for low temperature phase transitions. A low temperature single crystal X-ray diffraction experiment was performed on an Xcalibur Ruby Gemini Ultra at $123 \mathrm{~K}$ with an incremental scanning mode. Data were corrected for Lorentz and polarization effects and a multi-scan absorption correction was performed [13]. The structure was solved by direct methods using SIR92 [10] followed by a full-matrix least-squares refinement with SHELXL97 [11]. Hydrogen atom positions could be located from difference Fourier calculations and were refined without constraints but fixed $U_{\text {iso }}=0.025 \AA^{2}$, see Table 5. The Flack-parameters for both data sets are equal 0 within the tolerance. Further details of the measurement and refinement are collected in Table 1.

\section{Results and discussion}

1 crystallizes acentric in the orthorhombic space group $C m c 2_{1}$. Atomic coordinates and hydrogen bond lengths are collected in Tables 2 and 3, respectively. The DABCO dications take an eclipsed conformation with $C_{S}$-symmetry. However, especially $\mathrm{C} 3$ shows a pronounced elongation perpendicular to the mirror plane which might be regarded as a hint for dynamic behaviour. The ammonium $\mathrm{N}-\mathrm{H}$ groups and one ethylene group are located on the mirror plane, Wyckoff position $4 a$. The two ammonium protons of the dication are pointing towards one iodide ion $(\mathrm{N} 1$, $\mathrm{H} 1, \mathrm{I} 2)$ and towards a disordered oxygen site (N2, H2), respectively, which are able to act as hydrogen bond acceptors, see Figs. 2 and 3. The oxygen atom of the hydrate water molecule is statistically disordered on an $8 b$ Wyckoff position at a distance of $1.95 \AA$ from the $\mathrm{H} 2$ ammonium proton and 1.21 $\AA$ apart from a symmetry generated position. The distance between the ammonium proton and the hydrogen bonded iodide ion is $2.65 \AA$. The angles between the ammonium $\mathrm{N}-\mathrm{H}$ group and the hydrogen bond acceptor are $148^{\circ}$ for the water molecule and $150^{\circ}$ for the iodide, see Table 3 . The $\mathrm{N}-\mathrm{H} \cdots \mathrm{O}$ hydrogen bond lengths in the methanol solvate of DABCO dihydroiodide $(\mathrm{H} \cdots \mathrm{O}$ distances of 2.23 and $2.39 \AA, \mathrm{N} \cdots \mathrm{O}$

Table 2. Atomic coordinates $\left(\times 10^{4}\right)$ and equivalent isotropic displacement parameters $U_{\mathrm{eq}}{ }^{a}\left(\AA^{2} \cdot 10^{3}\right)$ of $\mathbf{1}$ at $293 \mathrm{~K}$.

\begin{tabular}{llllll}
\hline Atom & $\begin{array}{l}\text { Wyckoff } \\
\text { position }\end{array}$ & $x$ & $y$ & $z$ & $U_{\text {eq }}$ \\
\hline $\mathrm{I} 1$ & $4 a$ & $1 / 2$ & $8377(1)$ & $7996(1)$ & $46(1)$ \\
$\mathrm{I} 2$ & $4 a$ & 0 & $9877(1)$ & $1161(1)$ & $67(1)$ \\
$\mathrm{N} 1$ & $4 a$ & 0 & $7538(7)$ & $9745(8)$ & $43(2)$ \\
$\mathrm{N} 2$ & $4 a$ & 0 & $6347(6)$ & $8032(11)$ & $45(2)$ \\
$\mathrm{C} 1$ & $8 b$ & $8399(10)$ & $6872(6)$ & $9789(7)$ & $44(2)$ \\
$\mathrm{C} 2$ & $8 b$ & $8424(12)$ & $6152(7)$ & $8732(8)$ & $52(2)$ \\
$\mathrm{C} 3$ & $4 a$ & 0 & $7469(11)$ & $7600(12)$ & $77(4)$ \\
$\mathrm{C} 4$ & $4 a$ & 0 & $8163(8)$ & $8632(11)$ & $49(3)$ \\
$\mathrm{O}^{b}$ & $8 b$ & $9220(20)$ & $5657(10)$ & $5840(12)$ & $74(4)$ \\
\hline
\end{tabular}

a: $U_{\text {eq }}$ is defined as one third of the trace of the orthogonalized $U_{\mathrm{ij}}$ tensor; b: The oxygen site is occupied only by $50 \%$
Table 3. Hydrogen bond lengths/C-H $\cdots$ I contacts and angles in $\mathbf{1}$ at $293 \mathrm{~K}$ and at $123 \mathrm{~K}$.

\begin{tabular}{lllll}
\hline $\mathrm{T} / \mathrm{K}$ & $\mathrm{DH} \cdots \mathrm{A}$ & $\mathrm{H} \cdots \mathrm{A} / \AA$ & $\mathrm{D} \cdots \mathrm{A} / \AA$ & $\mathrm{D}-\mathrm{H} \cdots \mathrm{A} /{ }^{\circ}$ \\
\hline 293 & $\mathrm{~N} 2 \mathrm{H} \cdots \mathrm{O}$ & 1.95 & 2.77 & 148 \\
$\mathrm{~N} 1 \mathrm{H} \cdots \mathrm{I} 2$ & 2.65 & 3.46 & 150 \\
$\mathrm{OH} \cdots \mathrm{I} 2^{a}$ & - & 3.38 & - \\
$\mathrm{OH} \cdots \mathrm{I} 1^{a}$ & - & 3.59 & - \\
$\mathrm{C} 1 \mathrm{H} \cdots \mathrm{I} 1$ & 3.10 & 3.89 & 140 \\
$\mathrm{C} 4 \mathrm{H} \cdots \mathrm{I} 1$ & 3.11 & 3.97 & 144 \\
123 & $\mathrm{~N} 1 \mathrm{H} \cdots \mathrm{I} 2$ & 2.66 & 3.45 & 150 \\
$\mathrm{~N} 2 \mathrm{H} \cdots \mathrm{O}$ & 1.99 & 2.74 & 142 \\
$\mathrm{OH} \cdots \mathrm{I} 2$ & 2.74 & 3.51 & 172 \\
$\mathrm{OH} \cdots \mathrm{I} 1$ & 2.66 & 3.54 & 169 \\
$\mathrm{C} 1 \mathrm{H} \cdots \mathrm{I} 1$ & 3.06 & 3.82 & 141 \\
$\mathrm{C} 2 \mathrm{H} \cdots \mathrm{I} 1$ & 3.06 & 3.94 & 149 \\
$\mathrm{C} 3 \mathrm{H} \cdots \mathrm{I} 1$ & 3.04 & 3.88 & 143 \\
\hline
\end{tabular}

a: Hydrogen atoms of the water molecule could not be located at $293 \mathrm{~K}$

distances of 2.93 and $3.06 \AA$ ) are larger than in $\mathbf{1}$, and the angles therein are smaller $\left(133\right.$ and $\left.130^{\circ}\right)$, which might be caused by the size of the methanol molecule affecting the arrangement in the crystal. However, the $\mathrm{O}-\mathrm{H} \cdots \mathrm{N}$ distance of $1.92 \AA(\mathrm{O} \cdots \mathrm{N}$ distance of $2.74 \AA)$ in the methanol solvate of 1-methylated DABCO iodide fits very well to the $\mathrm{N}-\mathrm{H} \cdots \mathrm{O}$ distance in $\mathbf{1}$ [7]. The $\mathrm{O}-\mathrm{H} \cdots \mathrm{I}$ distances observed in the two methanol solvate compounds, being $2.70 \AA$ for both compounds $(\mathrm{O} \cdots \mathrm{I}$ distances of $3.51 \AA$ in $\mathrm{DABCO} 2 \mathrm{HI} \cdot 3 \mathrm{CH}_{3} \mathrm{OH}$ and $3.48 \AA$ in $\left.\mathrm{DABCOCH}_{3} \mathrm{I} \cdot 2 \mathrm{CH}_{3} \mathrm{OH}\right)$, are very similar to the $\mathrm{N}-\mathrm{H} \cdots \mathrm{I}$ distance observed in $\mathbf{1}$. However, they are pointing more directly towards the iodide ions with angles of $168^{\circ}$ (DABCO2 $\left.\mathrm{HI} \cdot 3 \mathrm{CH}_{3} \mathrm{OH}\right)$ and $160^{\circ}$ $\left(\mathrm{DABCOCH} \mathrm{I}_{3} \cdot 2 \mathrm{CH}_{3} \mathrm{OH}\right)$. DABCO hydroiodide monohydrate forms two polymorphs depending on the applied pressure. The $\mathrm{N}-\mathrm{H} \cdots \mathrm{O}$ and $\mathrm{O}-\mathrm{H} \cdots \mathrm{N}$ distances of 1.79 up to $1.95 \AA$ ( $\cdots$ O distances of 2.75 up to $2.82 \AA)$ in the two modifications are of the same order as in $\mathbf{1}$, but in average they are slightly shorter which might be caused by the high pressure. The shortest $\mathrm{O}-\mathrm{H} \cdots \mathrm{I}$ distances of $2.66(\alpha)$ and $2.57 \AA(\beta)$ are also very similar to those observed in 1 , but several additional $\mathrm{O}-\mathrm{H} \cdots \mathrm{I}$ contacts are observed in the $\alpha$-polymorph. These $\mathrm{H} \cdots \mathrm{I}$ distances are

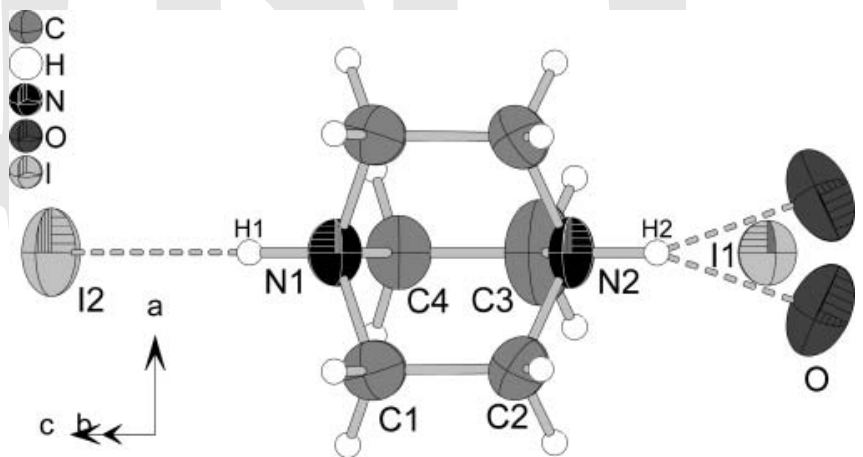

Fig. 2. Molecular arrangement and labeling scheme of $\mathbf{1}$ with hydrogen bonds $(293 \mathrm{~K})$. Ellipsoids are drawn at $50 \%$ level, hydrogen atoms are drawn at fixed level. 


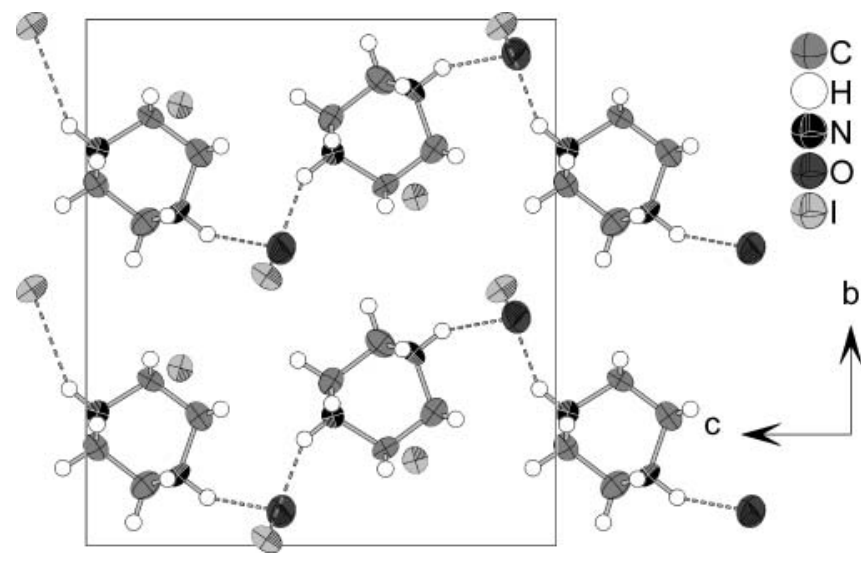

Fig. 3. Unit cell of 1 with hydrogen bonds (293 K). Ellipsoids are drawn at 50\% level, hydrogen atoms are drawn at fixed level.

2.94 up to $3.13 \AA$. The $\mathrm{N}-\mathrm{H} \cdots \mathrm{I}$ distances observed in $\mathbf{1}$ are $0.26 \AA$ shorter than those in the $\beta$-polymorph and 0.65 $\AA$ shorter than those in the $\alpha$-polymorph. A number of short $\mathrm{N}-\mathrm{H} \cdots \mathrm{N}$ hydrogen bonds can be observed in both polymorphs [8]. That type of interaction is observed very often within salts containing mono-protonated DABCO [14].

Two structures of DABCO dihydrochloride have also been described in literature. A DABCO di(hydrochloride) monohydrate however has not yet been observed. The dihydrochloride is known both as a dihydrate [6] and a water free compound [5]. In both compounds the ammonium $\mathrm{N}-\mathrm{H}$ bonds are pointing towards a hydrogen bond acceptor. In the water free compound two chloride ions form the hydrogen bonds with $\mathrm{H} \cdots \mathrm{Cl}$ distances and $\mathrm{N}-\mathrm{H} \cdots \mathrm{Cl}$ angles of $2.19 \AA / 151^{\circ}$ and $2.14 \AA / 174^{\circ}$ [5]. In the dihydrate one chloride ion and one oxygen atom of a water molecule act as hydrogen bond acceptors for the ammonium $\mathrm{N}-\mathrm{H}$ groups with an $\mathrm{O} \cdots \mathrm{H}$ distance and an $\mathrm{N}-\mathrm{H} \cdots \mathrm{O}$ angle of $1.77 \AA$ and $168^{\circ}$ and a $\mathrm{H} \cdots \mathrm{Cl}$ distance and an $\mathrm{N}-\mathrm{H} \cdots \mathrm{Cl}$ angle of $2.16 \AA$ and $156^{\circ}$ [6]. In both chlorides the ammonium $\mathrm{N}-\mathrm{H}$ bonds are pointing more directly towards an acceptor with angles between the bond and the acceptor closer to $180^{\circ}$ than in $\mathbf{1}$, see Table 3 .

In 1 numerous contacts are found mainly between the ethylene groups of the DABCO cations and the iodide

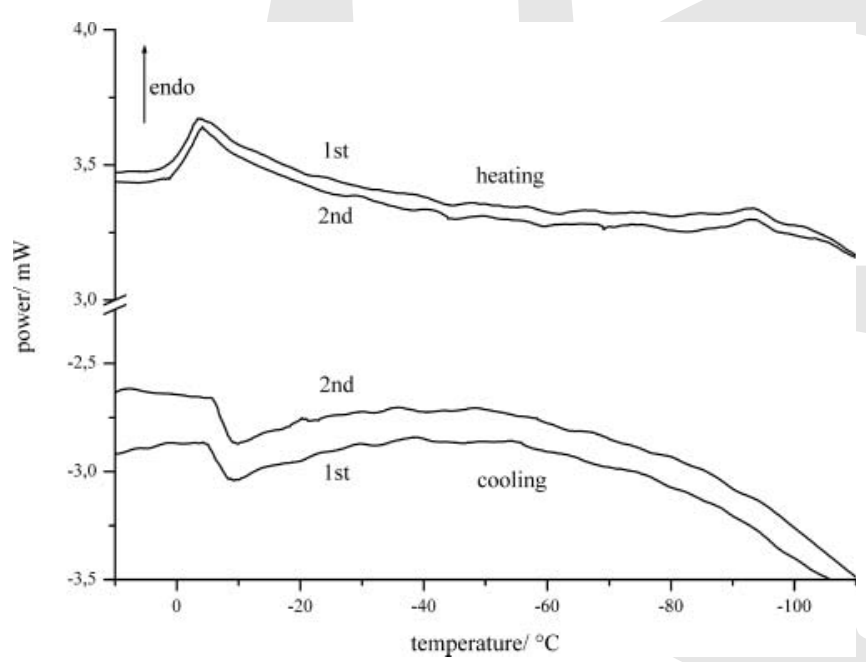

Fig. 4. DSC graph of 1 ions. The iodide ion which is forming the short hydrogen bond to the ammonium proton is surrounded by several hydrogen atoms in a range from 3.42 to $4.00 \AA$. The second iodide ion is forming two contacts with ammonium protons with $\mathrm{H} \cdots \mathrm{I}$ distances of $3.37 \AA$ and $3.54 \AA$ and several contacts to the ethylene hydrogen atoms in a range from 3.10 to $3.42 \AA$. However, these contacts and their contribution to hydrogen bonding cannot be quantified at the present state.

A DSC measurement was performed to check for phase transitions of $\mathbf{1}$ because an ordering of the hydrate water molecule is to be expected at low temperatures. The graph showed clear peaks for cooling and heating and confirmed a reversible phase transition at about $-8^{\circ} \mathrm{C}$, see Fig. 4. A single crystal diffraction experiment showed that the low temperature modification crystallizes acentric in space group $P c a 2_{1}$. A klassengleiche phase transition occurs upon cooling:

$$
C m c 2_{1}-\mathrm{k} 2,-b, a, c \rightarrow P c a 2_{1}
$$

This transition causes the loss of the $C$-centring. The DABCO molecule loses its $C_{S}$-symmetry with the carbon atoms $\mathrm{C} 1$ and $\mathrm{C} 2$ on the Wyckoff positions $8 b$ and takes a slightly staggered conformation with $\mathrm{N}-\mathrm{C}-\mathrm{C}-\mathrm{N}$ dihedral angles from 7 to $10.5^{\circ}$, six crystallographic independent carbon atom sites and distorted $D_{3}$-symmetry. In the lowtemperature phase all atoms occupy the Wyckoff position $4 a$. The hydrate water molecule is fully ordered on one site and even the positions of all hydrogen atoms can be refined without any restraints and fixed $U_{\text {iso }}=0.025 \AA^{2}$, see Fig. 5. A chain structure formed by hydrogen bonds of the hydrate water molecule and the ammonium $\mathrm{N}-\mathrm{H}$ groups can be observed just like in the structure of DAB$\mathrm{CO}$ dihydrochloride dihydrate, see Fig. 6 . The protons of the water molecule and the ammonium proton of the DABCO molecule form a nearly trigonal planar surrounding of the water oxygen atom. The lengths of $\mathrm{N}-\mathrm{H} \cdots \mathrm{O}$, $\mathrm{N}-\mathrm{H} \cdots \mathrm{I}$ hydrogen bonds and $\mathrm{C}-\mathrm{H} \cdots \mathrm{I}$ contacts, respectively, show no noticeable changes apart from some small shortening. By contrast, the $\mathrm{O}-\mathrm{H} \cdots \mathrm{I}$ bonds undergo some significant change due to the phase transition. The

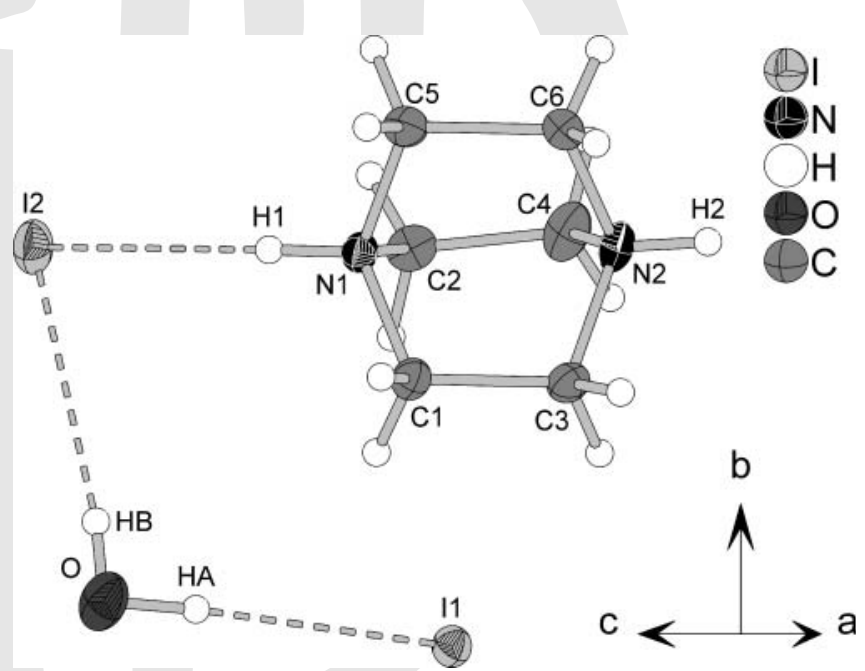

Fig. 5. Molecular arrangement and labeling scheme of 1 with hydrogen bonds $(123 \mathrm{~K})$. Ellipsoids are drawn at $50 \%$ level, hydrogen atoms are drawn at fixed level. 
Table 4. Atomic coordinates $\left(\times 10^{4}\right)$ and equivalent isotropic displacement parameters $U_{\mathrm{eq}}{ }^{a}\left(\AA^{2} \cdot 10^{3}\right)$ of $\mathbf{1}$ at $123 \mathrm{~K}$.

\begin{tabular}{llllll}
\hline Atom & $\begin{array}{l}\text { Wyckoff } \\
\text { position }\end{array}$ & $x$ & $y$ & $z$ & $U_{\text {eq }}$ \\
\hline $\mathrm{I} 1$ & $4 a$ & $9149(1)$ & $2653(1)$ & $7651(1)$ & $17(1)$ \\
$\mathrm{I} 2$ & $4 a$ & $7633(1)$ & $7694(1)$ & $820(1)$ & $23(1)$ \\
$\mathrm{N} 1$ & $4 a$ & $9985(2)$ & $7627(3)$ & $9378(2)$ & $15(1)$ \\
$\mathrm{N} 2$ & $4 a$ & $1196(2)$ & $7696(3)$ & $7684(3)$ & $19(1)$ \\
$\mathrm{O}$ & $4 a$ & $8128(2)$ & $3221(3)$ & $499(2)$ & $29(1)$ \\
$\mathrm{C} 1$ & $4 a$ & $651(2)$ & $6027(3)$ & $9415(3)$ & $17(1)$ \\
$\mathrm{C} 2$ & $4 a$ & $9366(2)$ & $7681(4)$ & $8276(3)$ & $20(1)$ \\
$\mathrm{C} 3$ & $4 a$ & $1306(2)$ & $5983(3)$ & $8302(2)$ & $17(1)$ \\
$\mathrm{C} 4$ & $4 a$ & $106(3)$ & $7889(4)$ & $7255(3)$ & $25(1)$ \\
$\mathrm{C} 5$ & $4 a$ & $661(2)$ & $9213(3)$ & $9484(3)$ & $17(1)$ \\
$\mathrm{C} 6$ & $4 a$ & $1458(2)$ & $9178(4)$ & $8489(3)$ & $21(1)$ \\
\hline
\end{tabular}

a: $U_{\text {eq }}$ is defined as one third of the trace of the orthogonalized $U_{i j}$ tensor

two different $\mathrm{O} \cdots \mathrm{I}$ distances become nearly equivalent at $123 \mathrm{~K}$ with a difference of only $0.03 \AA$. At $293 \mathrm{~K}$ the difference is $0.21 \AA$, see Table 3 . Unfortunately the hydrogen bond lengths cannot be compared directly, because the hydrogen atoms of the water molecule could not be located at $293 \mathrm{~K}$.

The IR-spectrum of $\mathbf{1}$ is displayed in Fig. 7. It shows two peaks at 3403 and $3354 \mathrm{~cm}^{-1}$ for the $\mathrm{O}-\mathrm{H}$ stretching modes. The stretching modes are red-shifted as compared to the free water molecule in the gas phase of $3756\left(v_{\mathrm{sym}}\right)$ and $3657 \mathrm{~cm}^{-1}\left(v_{\text {asym }}\right)$. It is known that this shift is caused by the formation of hydrogen bonds and depends strongly on the type of the hydrogen bond acceptor atom or molecule. The energy range of the $\mathrm{O}-\mathrm{H}$ stretching modes is 3600 to $3000 \mathrm{~cm}^{-1}$ in solid hydrates. The iodide ions in $\mathbf{1}$ are good acceptors for the hydrogen bonds of the hydrate water molecule. This explains the significant red-shift of

Table 5. Hydrogen atom coordinates $\left(\times 10^{4}\right)$ of $\mathbf{1}$ at $123 \mathrm{~K}^{a}$.

\begin{tabular}{lrrr}
\hline Atom & \multicolumn{1}{l}{ x } & \multicolumn{1}{l}{ y } \\
\hline H1 & $9560(40)$ & $7670(40)$ & $9970(40)$ \\
H2 & $1640(30)$ & $7780(40)$ & $7090(30)$ \\
HA & $8460(30)$ & $3090(50)$ & $9800(30)$ \\
HB & $8020(30)$ & $4230(50)$ & $500(30)$ \\
H1A & $200(30)$ & $5080(40)$ & $9400(30)$ \\
H1B & $1030(30)$ & $6000(60)$ & $110(30)$ \\
H2A & $9000(30)$ & $6570(50)$ & $8160(30)$ \\
H2B & $8920(30)$ & $8550(50)$ & $8340(30)$ \\
H3A & $1070(20)$ & $5080(40)$ & $7750(30)$ \\
H3B & $2090(30)$ & $5850(40)$ & $8430(30)$ \\
H4A & $60(30)$ & $9030(40)$ & $6980(30)$ \\
H4B & $9940(30)$ & $7080(40)$ & $6680(40)$ \\
H5A & $210(30)$ & $180(40)$ & $9440(30)$ \\
H5B & $980(30)$ & $9220(60)$ & $220(30)$ \\
H6A & $1440(30)$ & $210(40)$ & $8060(30)$ \\
H6B & $2140(30)$ & $9010(40)$ & $8750(30)$ \\
\hline
\end{tabular}

a: A value of $0.025 \AA^{2}$ for $U_{\text {eq }}$ was fixed for all hydrogen atoms

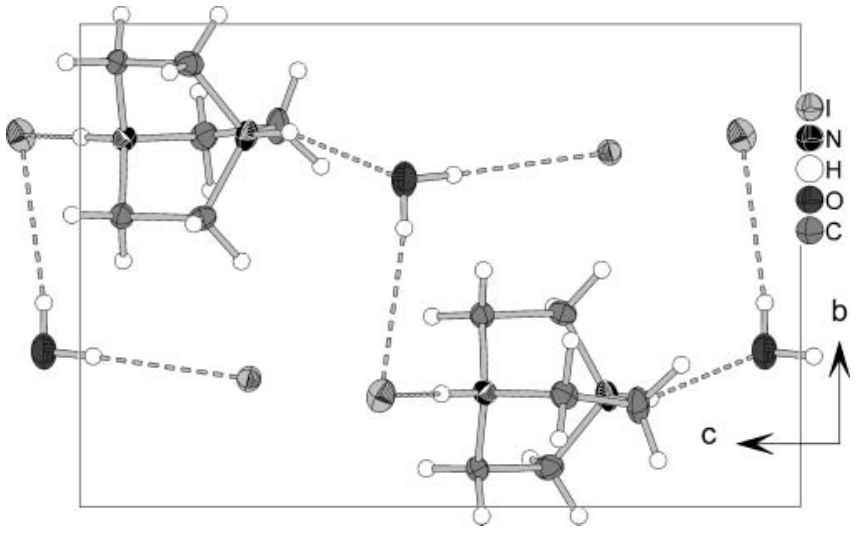

Fig. 6. Unit cell of $\mathbf{1}$ with hydrogen bonds (123 K). Ellipsoids are drawn at $50 \%$ level, hydrogen atoms are drawn at fixed level.

the vibrational frequencies. Since the water molecule in $\mathbf{1}$ is also a hydrogen bond acceptor via the oxygen lone pair the acidity of the water protons is increased, which strengthens the hydrogen bonds to the iodide ions [15]. Table 3 displays only the shortest $\mathrm{C}-\mathrm{H} \cdots \mathrm{I}$ contacts. Numerous other contacts can be observed with longer $\mathrm{H} \cdots \mathrm{I}$ distances of 3.09 up to $3.25 \AA$, which are all pointing towards the atom I1. The shortest $\mathrm{C}-\mathrm{H} \cdots \mathrm{I} 2$ hydrogen contact is $3.27 \AA$. The atom I 2 is exclusively coordinated by short hydrogen bonds of the ammonium $\mathrm{N}-\mathrm{H}$ group and the water molecule which might be sufficient to stabilize the negative charge.

Vibration modes of $\mathbf{1}\left(\mathrm{cm}^{-1}\right)$ at room temperature:

IR (Fig. 7): v (O-H) $3403(\mathrm{~m}), 3354$ (m); v (C-H) 3006 (m), 2968 (w), 2898 (m), 2809 (m), 2748 (m), 2719 (w); $v(\mathrm{~N}-\mathrm{H}) 2628(\mathrm{~m}), 2559(\mathrm{w}) ; v(\mathrm{~N}-\mathrm{C}$ and $\mathrm{C}-\mathrm{C})$, deformation vibrations $1596(\mathrm{~m}), 1490$ (m), 1467 (m), 1445 (m), 1420 (m), 1396 (w), 1383 (s), 1363 (w), 1322 (w), 1309 (m), 1281 (w), 1255 (w), 1203 (m), 1183 (m), 1160 (m), 1051 (s), 989 (w), 968 (m), 888 (m), 837 (s), 791 (m), 598 (w), 488 (m), 437 (m)

Raman: $v(\mathrm{~N}-\mathrm{H}$ and $\mathrm{C}-\mathrm{H}) 3011$ (s), 2997 (w), 2958 (s), $2935(\mathrm{w}), 2901(\mathrm{~m}): v(\mathrm{~N}-\mathrm{C}$ and $\mathrm{C}-\mathrm{C})$, deformation vibrations 1597 (w), 1493 (w), 1450 (m), 1390 (m), 1308

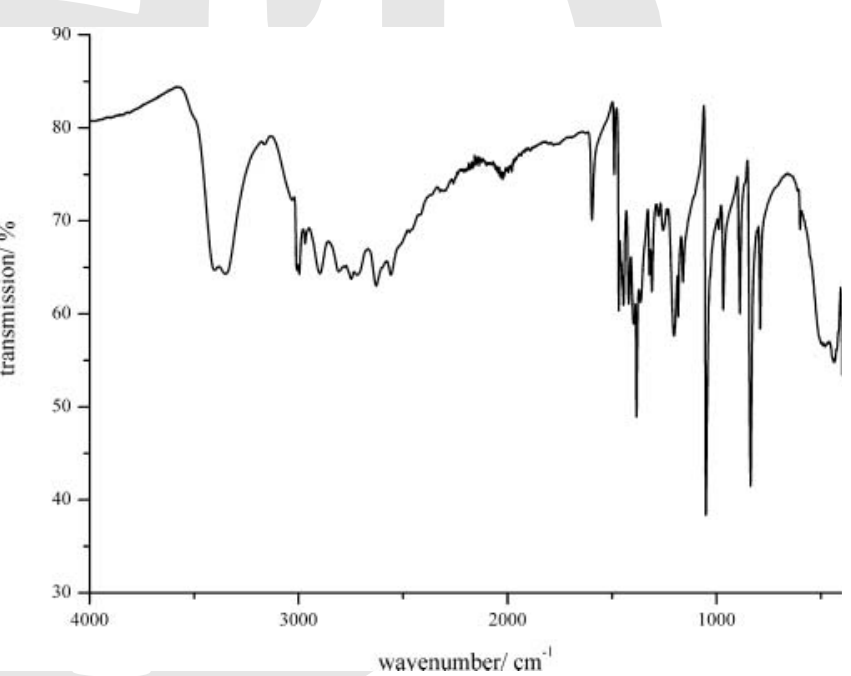

Fig. 7. IR-spectrum of 1 at $293 \mathrm{~K}$. 
(w), $1253(\mathrm{~m}), 1183(\mathrm{~m}), 1160(\mathrm{w}), 1051(\mathrm{~s}), 968(\mathrm{w})$, 893 (m), 842 (w), 794 (s), 600 (m), 552 (w), 399 (m)

$$
S=\sqrt{\frac{\sum_{h k l} w\left(F_{\mathrm{o}}^{2}-F_{\mathrm{c}}^{2}\right)^{2}}{m-n}}
$$

$m=$ number of reflections, $n=$ number of parameters

$$
\begin{aligned}
& R_{1}=\frac{\sum_{h k l}|| F_{\mathrm{o}}|-| F_{\mathrm{c}}||}{\sum_{h k l}\left|F_{\mathrm{o}}\right|} \\
& w R_{2}=\sqrt{\frac{\sum_{h k l} w\left(F_{\mathrm{o}}^{2}-F_{\mathrm{c}}^{2}\right)^{2}}{\sum_{h k l} w\left(F_{\mathrm{o}}^{2}\right)^{2}}} \\
& w=1 /\left\lfloor\sigma^{2}\left(F_{\mathrm{o}}^{2}\right)+(a P)^{2}+b P\right\rfloor \\
& P=\left[2 F_{\mathrm{c}}^{2}+\operatorname{Max}\left(F_{\mathrm{o}}^{2}, 0\right)\right] / 3
\end{aligned}
$$

Acknowledgements. The authors thank Dr. M. Bodensteiner for the low temperature X-ray diffraction measurement and U. Schieß1 for DSC measurements. Vibration spectra were recorded by D. Garcia.

\section{References}

[1] a) K. Kranjc, M. Kočevar, Ethyl Vinyl Ether as a Synthetic Equivalent of Acetylene in a DABCO-Catalyzed Microwave-Assisted Diels-Alder-Elimination Reaction Sequence Starting from 2H-Pyran-2-ones. Synlett 2008, 17, 2613-2616; b) H. M. Meshram, P. Ramesh, A. S. Kumar, A. Swetha, An efficient and environmentally friendly DABCO catalyzed Henry reaction of isatins. Tetrahedron Letters 2011, 52, 5862-5864.
[2] D. A. Guzonas, D. E. Irish, A Raman and infrared spectroscopic study of triethylenediamine (DABCO) and its protonated forms. Can. J. Chem. 1988, 66, 1249-1257.

[3] H. S. Harned, N. D. Embree, The ionization constant of formic acid from 0 to $60^{\circ}$ C. J. Am. Chem. Soc. 1934, 56, 1042-1044.

[4] N. E. Vanderborgh, Evaluation of the lanthanum fluoride membrane electrode response in acetic solutions. Talanta 1968, 15, 1009-1013.

[5] S. W. Kennedy, P. K. Schultz, P. G. Slade, E. R. T. Tiekink, Triethylenediamine dihydrochloride Z. Kristallogr. 1987, 180, 211.

[6] T. C. Lewis, D. A. Tocher, A low-temperature determination of triethylenediaminium dichloride dihydrate. Acta Crystallogr., Sect. E: Struct. Rep. Online 2005, 61, o2202.

[7] A. Olejniczak, A. Katrusiak, Pressure induced transformations of 1,4-diazabicyclo[2.2.2] octane (dabco) hydroiodide: diprotonation of dabco, its $N$-methylation and co-crystallization with methanol. Cryst. Eng. Comm. 2010, 12, 2528-2532.

[8] A. Olejniczak, A. Katrusiak, Pressure-induced hydration of 1,4diazabicyclo[2.2.2] octane hydroiodide (dabcoHI). Cryst. Growth Des. 2011, 11, 2250-2256.

[9] X-RED 1.26, Program for data reduction; X-SHAPE 2.05, Program for crystal optimization for numerical apsorption correction, 2004, STOE \& Cie, Darmstadt, Germany.

[10] A. Altomare, G. Cascarano, C. Giacovazzo, A. Gualardi, Completion and refinement of crystal structures with SIR92. J. Appl. Cryst. 1993, 26, 343-350.

[11] G. M. Sheldrick, SHELXL-97, 1997, Universität Göttingen, Göttingen, Germany.

[12] Resolutions Pro Software, Molecular Spectroscopy Solutions, Varian Inc., Version 4.1.0.101, 2006.

[13] CrysAlisPro Software, Agilent Technologies, Version 1.171.35.11, 2011

[14] A. Katrusiak, M. Ratajczak-Sitarz, E. Grech, Stereochemistry and transformations of $\mathrm{NH}-\mathrm{N}$ hydrogen bonds Part II. Proton stability in the monosalts of 1,4-diazabicyclo[2.2.2]octane. $J$. Mol. Struct. 1999, 474, 135-141.

[15] H. D. Lutz, Bonding and structure of water molecules in Solid Hydrates. Correlation of spectroscopic and structural data. Structure and Bonding 1988, 69, 97-125. 